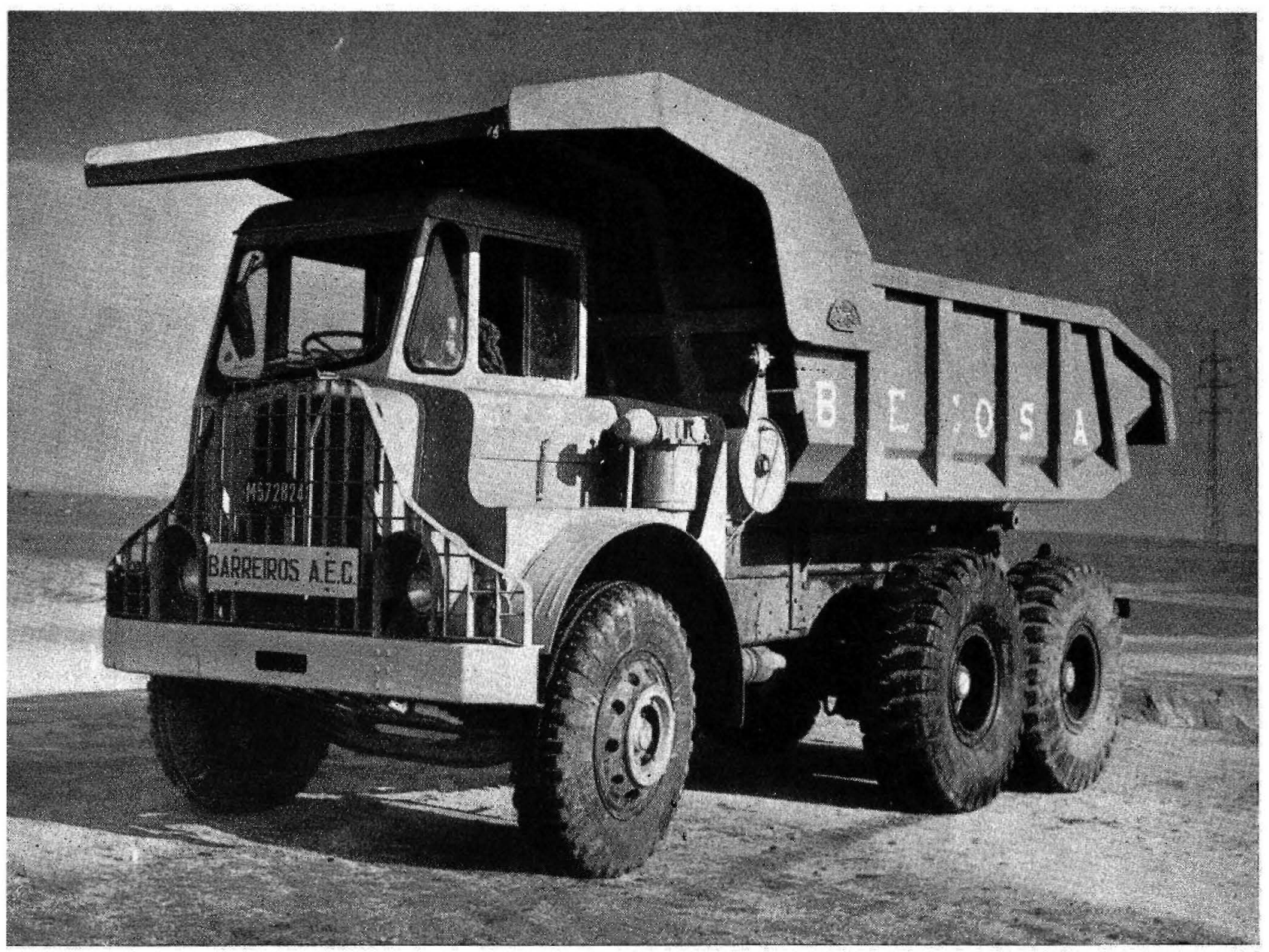

\title{
el Dumper de 7,65 metros cúbicos Barreiros A. E. C.
}

Las cajas con que va equipado están en consonancia con los trabajos a realizar:

CAJA STANDARD, de 8 a $9 \mathrm{~m}^{2}$ de capacidad.

CAJA PARA TRABAJO EN CANTERAS (ROCAS), de 6 a $7 \mathrm{~m}^{3}$.

CAJA PARA TRANSPORTES DE CARBON, de $15 \mathrm{~m}^{3}$ de capacidad.

Las cargas pueden variar entre 12,5 y $15 \mathrm{t}$, según el tipo de caja. Está impulsado por un motor Diesel de 6 cilindros A. E. C., de $192 \mathrm{HP}$, acoplado a una caja de cambios de cinco velocidades, de toma constante.

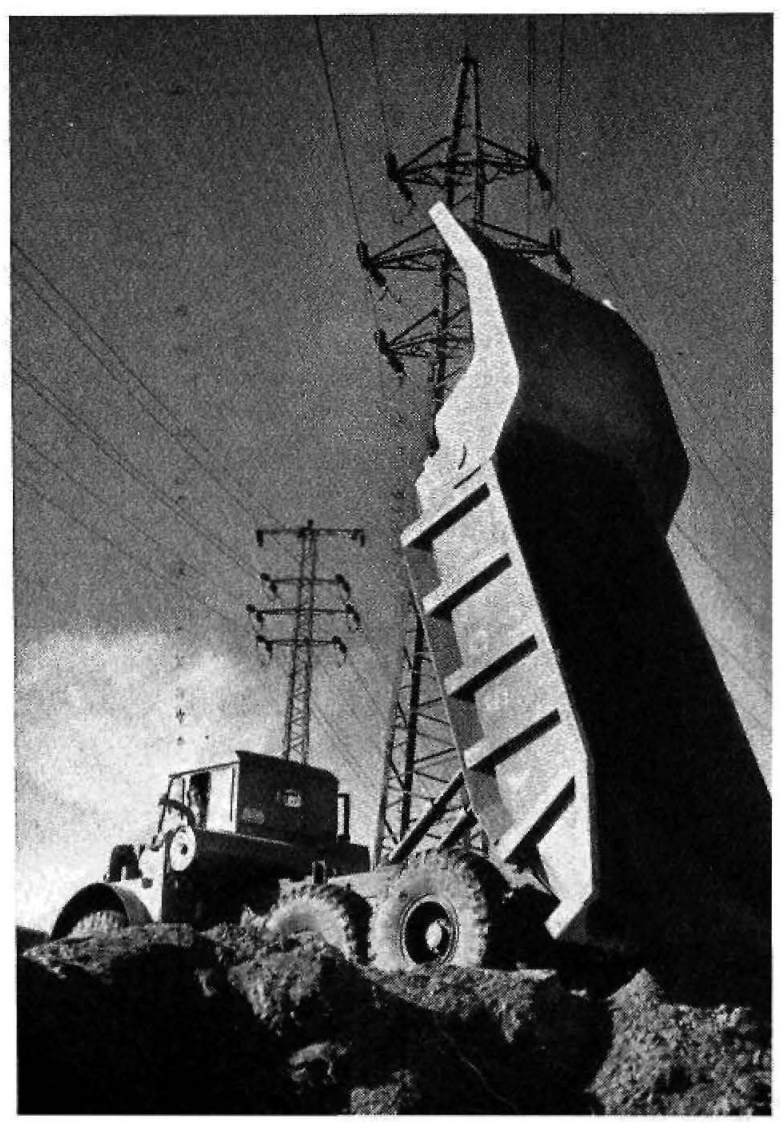




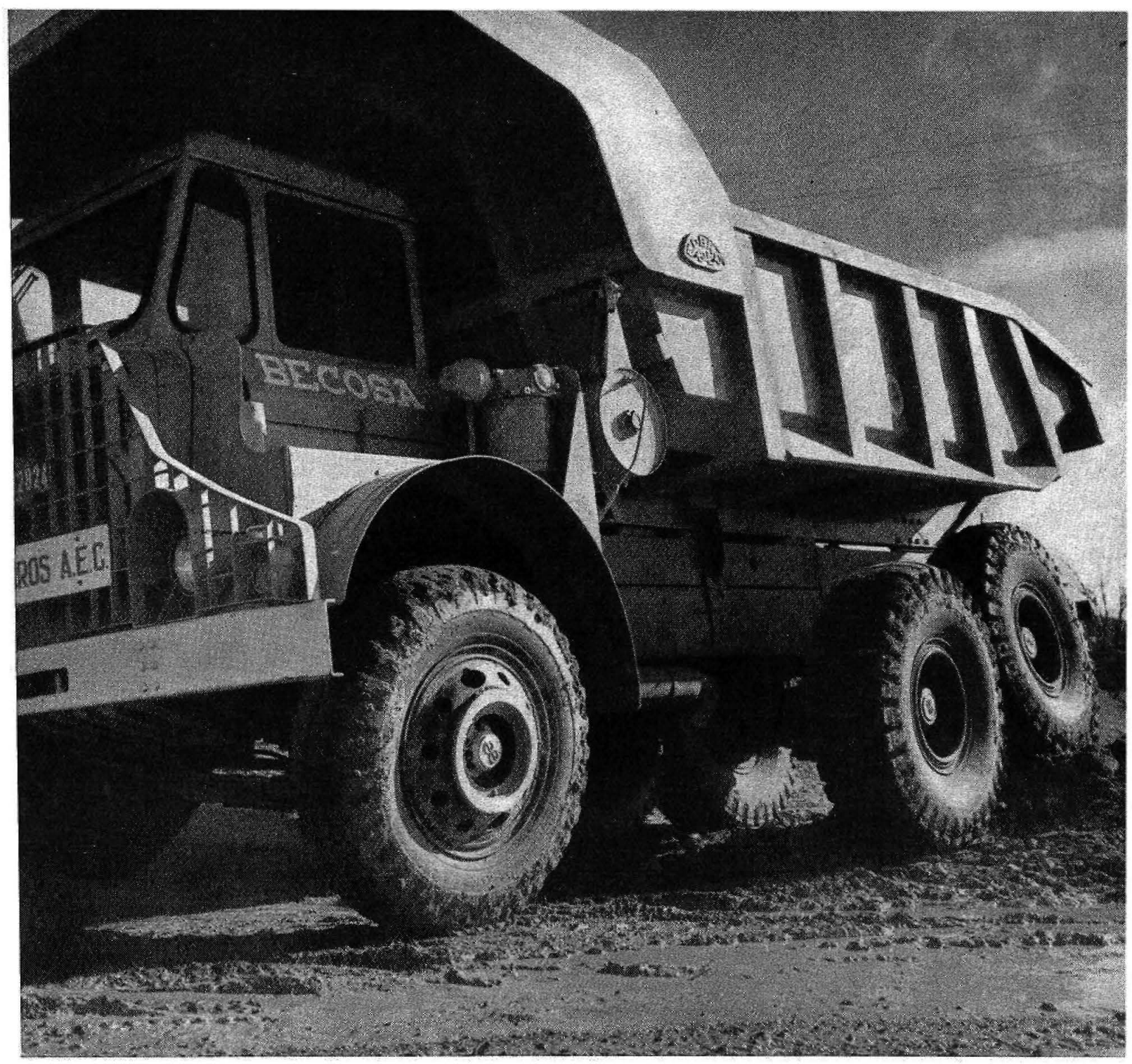

El eje trasero, doble, totalmente articulado, permite la adaptación de las cuatro ruedas al terreno de superficie irregular, consiguiéndose la adherencia necesaria aun en condiciones desfavorables.

El equipo de vuelco está constituido por dos cilindros hidráulicos de tres cuerpos, proporcionando una descarga en 12-14 segundos con retroceso rápido e inclinación máxima de la caja de $70^{\circ}$. Los cilindros son de doble acción en sus dos últimas posiciones.

Freno de emergencia.-La operación de frenado mecánico sobre el freno posterior se lleva a efecto mediante una palanca de accionamiento repetido. El equipo eléctrico es de 24 voltios.

Caja standard.-Está construida con perfiles de acero de sección acanalada, reforzada en su parte inferior con perfiles estampados. El suelo está formado por tres capas: la primera, de chapa, de $4,8 \mathrm{~mm}$; la segunda, de madera endurecida, de $51 \mathrm{~mm}$, y la tercera, también de chapa, de 6,4 milímetros.

En la vista en planta de la caja se puede observar que ésta se abre progresivamente hacia la parte posterior, lo que, unido a los grandes radios de los ángulos y rincones, proporciona al bascular una descarga limpia.

Caja para trabajos de canteras.-Es de las mismas características, aunque de constitución más robusta.

Caja para transporte de carbón.-Tiene un ángulo de basculación ligeramente menor. La parte posterior es de tipo compuerta, con dos bisagras y cierre sencillo por sistema de excéntrica.

Pala de arrastre,-En la parte delantera del vehículo puede colocarse una pala de arrastre de control hidráulico. Una articulación automática patentada levanta la cuchilla antes de que ésta resulte sobrecargada.

M. CHINCHILLA 